\title{
Nanoparticle-based strategy for personalized B-cell lymphoma therapy
}

\author{
This article was published in the following Dove Press journal: \\ International Journal of Nanomedicine \\ 16 November 2016 \\ Number of times this article has been viewed
}

\section{Nicola M Martuccil,* \\ Nunzia Migliacciol,* \\ Immacolata Ruggiero',* \\ Francesco Albano ${ }^{2}$ \\ Gaetano Cali ${ }^{3}$ \\ Simona Romano' \\ Monica Terracciano 4 \\ Ilaria Rea ${ }^{4}$ \\ Paolo Arcari' \\ Annalisa Lamberti'}

'Department of Molecular Medicine and Medical Biotechnology, University

Federico II of Naples, Naples,

${ }^{2}$ Department of Experimental and

Clinical Medicine, University of

Catanzaro "Magna Graecia”, Catanzaro,

${ }^{3}$ Institute of Endocrinology and

Molecular Oncology, ${ }^{4}$ Institute for

National Research Council,

Naples, Italy

*These authors contributed equally to this work
Microelectronics and Microsystems,

\footnotetext{
Correspondence: Annalisa Lamberti Department of Molecular Medicine and Medical Biotechnology, University Federico II of Naples, via Sergio Pansini 5. 8013 I Naples, Italy

Tel +398174631 I9

Fax +39817463653

Email annalisa.lamberti@unina.it
}

\begin{abstract}
B-cell lymphoma is associated with incomplete response to treatment, and the development of effective strategies targeting this disease remains challenging. A new personalized B-cell lymphoma therapy, based on a site-specific receptor-mediated drug delivery system, was developed in this study. Specifically, natural silica-based nanoparticles (diatomite) were modified to actively target the antiapoptotic factor B-cell lymphoma/leukemia 2 (Bcl2) with small interfering RNA (siRNA). An idiotype-specific peptide (Id-peptide) specifically recognized by the hypervariable region of surface immunoglobulin B-cell receptor was exploited as a homing device to ensure specific targeting of lymphoma cells. Specific nanoparticle uptake, driven by the Id-peptide, was evaluated by flow cytometry and confocal microscopy and was increased by approximately threefold in target cells compared with nonspecific myeloma cells and when a random control peptide was used instead of Id-peptide. The specific internalization efficiency was increased by fourfold when siRNA was also added to the modified nanoparticles. The modified diatomite particles were not cytotoxic and their effectiveness in downregulation of gene expression was explored using siRNA targeting Bcl2 and evaluated by quantitative real-time polymerase chain reaction and Western blot analyses. The resulting gene silencing observed is of significant biological importance and opens new possibilities for the personalized treatment of lymphomas.
\end{abstract}

Keywords: diatomite, active targeting, Bcl2, small interfering RNA, personalized therapy

\section{Introduction}

Cancer is one of the leading causes of death worldwide. Currently, cancer treatments, including radiations and chemotherapeutics, present a range of critical drawbacks, including low treatment efficiency and serious side effects, due to nonspecific impairment of normal tissues and cells. Targeted drug delivery and release to tumor sites is believed to enhance therapeutic efficiency and limit side effects. Subsequent to the discovery of the first drug delivery system based on liposomes in the 1960s, nanomedicine has made significant advances in the pharmaceutical and biotechnology fields. ${ }^{1-10}$

Gene therapy using small interfering RNA (siRNA) to downregulate the expression of cancer-associated genes represents a promising tool in cancer treatment. ${ }^{11-13}$ However, naked siRNA is susceptible to enzymatic degradation and is thus not able to survive in biological fluids for extended periods of time. Moreover, the ability of siRNA molecules to penetrate the cell membrane is limited by their strong negative charge and high molecular weight. Thus, successful RNA interference therapy is considerably reliant on the development of efficient gene delivery systems.

A wide range of nanomaterials have been explored for siRNA delivery, and, among them, inorganic systems based on silica are the most attractive bio-interfaces, since 
they couple interesting properties with reduced toxicity. ${ }^{14-16}$ In addition, silica is one of the few inorganic materials recognized as "safe" by the US Food and Drug Administration. In this study, diatomite-based nanoparticles were employed as a delivery platform to specifically vehiculate siRNA to lymphoma cancer cells. ${ }^{17-20}$

B-cell lymphoma is a clonal expansion of neoplastic cells that can have a fatal outcome. Tumorigenic B-cell lymphomas are sensitive to conventional anticancer treatments, including chemotherapy, radiation, and corticosteroids; however, the disease is associated with incomplete response to clinical treatment, resulting in a minimal residual disease, where some undetected cancerous cells supply the cancer cell reservoir in vivo. ${ }^{21}$ Despite considerable efforts in lymphoma therapy, the development of an effective strategy to target the anatomic homing of tumorigenic B cells still remains challenging.

B-cell lymphoma/leukemia 2 ( $\mathrm{Bcl} 2)$ is an apoptosisregulating protein, and its overexpression is associated with an abnormal apoptotic pathway conferring a protective effect toward death signals on malignant cells. Impairment of Bcl2 has been identified as contributing to the onset of a large number of cancers, including lymphoma. ${ }^{22} \mathrm{Bcl} 2$ overexpression results in chemotherapy-resistant disease, an aggressive clinical course and poor survival in patients with B-cell lymphoproliferative disorders. ${ }^{23-25}$ A successfully developed Bcl2-targeted drug has the potential to enhance cell killing, when used in combination with traditional cytotoxic agents. ${ }^{26}$ Attempts to downregulate $\mathrm{Bcl} 2$ by antisense therapy have been pursued as an antitumor strategy. ${ }^{27,28}$

In this study, an active targeting strategy for Bcl2 siRNA delivery was developed to specifically target extremely aggressive murine A20 lymphoma cells, using as ligand an idiotype-specific peptide (Id-peptide) endowed with high affinity toward B-cell receptor (BCR, homing device). ${ }^{29,30}$ The idiotype determinants of the immunoglobulin B-cell receptor (Ig-BCR) of B-cell malignancies are unique for a given clonal population and function as patient-specific tumor antigen that may be exploited for active therapeutic targeting in personalized cancer therapy. ${ }^{30}$ The choice of Idpeptides was based on the following properties: 1) binding to tumor target cells with high specificity and sensitivity, both in vitro and in vivo, and 2) internalization into target tumor cells by BCR-mediated endocytosis, which overcomes drug resistance. ${ }^{29-31}$ Based on these considerations, diatomite nanoparticles (DNPs) conjugated with an Id-peptide and loaded with siRNA directed against $B c l 2$, highly expressed in most B-cell lymphomas, were explored as a ligand-mediated delivery platform.

\section{Materials and methods \\ Reagents}

Calcined diatomite was obtained from Deref Spa (Genova, Italy); 3-(4,5-dimethythiazol-2-yl)-2,5-diphenyl tetrazolium bromide (MTT), (3-aminopropyl)triethoxysilane (APTES), $N$-hydroxysuccinimide (NHS), $N$-(3-dimethylaminopropyl)$N^{\prime}$-ethylcarbodiimide hydrochloride (EDC), MES buffer, propidium iodide (PI) and $\mathrm{H}_{2} \mathrm{SO}_{4}$ were purchased from Sigma-Aldrich (St Louis, MO, USA). Phosphate-buffered saline (PBS) was purchased from Gibco (Grand Island, NY, USA). ON-TARGET plus smart pool mouse Bcl2 (siRNA Bcl2), ON-TARGET plus control pool nontargeting pool (siRNA scramble, siRNASCR) and fluorescent (Dy547) siGLO RISC-Free siRNA (siRNA*) were from Thermo Fisher Scientific (Waltham, MA, USA). Synthesis of poly D-Arg peptide (sequence RRRRRRRRC) was performed by ProteoGenix (Schiltigheim, France). $\mathrm{HCl}$ was purchased from ROMIL (Cambridge, UK). A20 target-specific peptide (pA2036) (sequence EYVNCDNLVGNCVI), pA2036-9R [sequence EYVNCDNLVGNCVI-(L-Arg)8(D-Arg)], pA2036-fluorescein isothiocyanate (FITC) (pA2036*) random peptide (pRND) (sequence SSAYGSCKGPCSSGVHSI), pRND-9R [sequence SSAYGSCKGPCSSGVHSI(LArg)8(D-Arg)], and pRND-FITC (pRND*) were synthetized by CASLO Laboratory, Lyngby, Denmark. Cell-Titer GLO was purchased from Promega (Madison, WI, USA).

\section{Preparation of modified DNPs}

The diatomite nanopowder was obtained from calcined diatomite as already reported and purified with hot strong acids to remove organic and inorganic contaminants. ${ }^{17}$ After purification treatments, DNPs were aminosilanized by $1 \mathrm{~h}$ incubation at room temperature (RT) with a 5\% (v/v) APTES solution in absolute ethanol to form a thin silane film on their surface..$^{32,33}$ The amino groups of silanized DNPs were covalently conjugated to the carboxyl groups of peptides alone and/or complexed with siRNA via NHS/EDC chemistry; briefly, DNPs $(\sim 1.0 \mathrm{mg})$ were incubated with $150 \mu \mathrm{M}$ peptide in the presence of EDC $(20 \mathrm{mM}) / \mathrm{NHS}(12 \mathrm{mM})$ solution in $10 \mathrm{mM}$ MES buffer $\mathrm{pH} 5.5$ to promote the reaction (ON at RT, under stirring). Peptide/siRNA complex was previously obtained by mixing $150 \mu \mathrm{M}$ peptide with $7.5 \mu \mathrm{M}$ siRNA (molar ratio 20:1) for $2 \mathrm{~h}$ at $\mathrm{RT}$ in PBS pH 7.4. After the reaction, diatomite suspension was centrifuged and the pellet 
was collected and washed twice with PBS. The siRNA loaded was $\sim 0.5$ pmol per $1.0 \mu \mathrm{g}$ of diatomite, as determined by UV reading at $260 \mathrm{~nm}$.

\section{Size and morphology of DNPs}

Morphology of bare DNPs was investigated by atomic force microscopy (AFM). A XE-100 AFM (Park Systems) was used for the imaging of DNPs deposited on silicon substrate. Surface imaging was obtained in noncontact mode using silicon/aluminum-coated cantilevers (PPP-NCHR $10 \mathrm{M}$; Park Systems) $125 \mu \mathrm{m}$ long with a resonance frequency of $200-400 \mathrm{kHz}$ and a nominal force constant of $42 \mathrm{~N} / \mathrm{m}$. The scan frequency was typically $1 \mathrm{~Hz}$ per line.

The size and surface charge measurements of DNPs dispersed in water $(\mathrm{pH} \mathrm{7)}$ were investigated by dynamic light scattering (DLS) using a Zetasizer Nano ZS (Malvern Instruments, UK) equipped with a $\mathrm{He}-\mathrm{Ne}$ laser $(633 \mathrm{~nm}$, fixed scattering angle of $173^{\circ} \mathrm{C}, 25^{\circ} \mathrm{C}$ ).

\section{Cells and reagents}

A20 is a murine cell line derived from a spontaneously arising tumor in an aged BALB/c mouse. It pathologically mimics the characteristics of human diffuse large B-cell lymphoma. ${ }^{29,34}$ The 5T33 murine myeloma (5T33MM) cells were used as control. The cell lines were kindly provided by Prof C Palmieri (University of Catanzaro, Italy). The cell lines were grown in suspension culture with Roswell Park Memorial Institute (RPMI) 1640 medium (Gibco), supplemented with $10 \%$ fetal bovine serum (FBS; Gibco), 50 units $/ \mathrm{mL}$ penicillin, $50 \mu \mathrm{g} / \mathrm{mL}$ streptomycin and $2 \mathrm{mM}$ L-glutamine at $37^{\circ} \mathrm{C}$ in a $5 \% \mathrm{CO}_{2}$ atmosphere. Human peripheral blood mononuclear cells (PBMCs) from healthy donors were obtained from heparinized peripheral blood samples by centrifugation $(400 \times g$ for $30 \mathrm{~min})$ over a Ficoll-Hipaque (Lonza, MD, USA) density gradient. Cells were resuspended in RPMI 1640 medium supplemented with 10\% FBS.

\section{Cytofluorimetric analysis}

Cell lines $\left(2.0 \times 10^{6}\right)$ were incubated with pA2036- or pRND FITC-functionalized DNPs (DNPs•pA2036*/pRND*) at $50 \mu \mathrm{g} / \mathrm{mL}$ for $2 \mathrm{~h}$ at $37^{\circ} \mathrm{C}$. After three washes in PBS, cells were divided into two aliquots; the first aliquot was resuspended in PBS and the other aliquot was permeabilized using $2 \%$ paraformaldehyde at RT for $30 \mathrm{~min}$, washed twice with PBS and incubated with $0.1 \%$ Triton X-100 in PBS on ice for 1-2 min. After washing, the cells were resuspended in PBS, and both aliquots were treated with $0.002 \%$ Trypan blue solution (Sigma-Aldrich) for $10 \mathrm{~min}$ to quench extracellular fluorescence and analyzed with a Becton Dickinson FACScan flow cytometer. The same procedure was performed on A20 cells treated with pA2036-9R・siRNA*(DNPs•pA20369R・siRNA*) or on A20 cells and PBMCs treated with pA2036- and polyArg•siRNA*-functionalized DNPs (DNPs•pA2036•polyArg•siRNA*) with the respective negative controls. All measurements were carried out in triplicate, in three independent experiments.

\section{Confocal microscopy}

A20 cells $\left(2.0 \times 10^{6}\right)$ were treated with DNPs•pA2036* $(50 \mu \mathrm{g} / \mathrm{mL})$ for 30,60 , and $120 \mathrm{~min}$. After washing with PBS, the cells were incubated with $0.5 \%$ CellMask Deep Red (Molecular Probes, Thermo Fisher Scientific) in Live Cell Imaging Solution according to the manufacturer's instructions. Successively, cells were fixed with $2 \%$ paraformaldehyde at RT for $10 \mathrm{~min}$, washed twice with PBS and, 5 min before confocal analysis, NucBlue (Molecular Probes) was added following manufacture's instructions. Cells were then spotted on microscope slides and analyzed. Experiments were carried out on an inverted and motorized microscope (Axio Observer Z.1) equipped with a $63 \times / 1.4$ Plan-Apochromat objective. The attached laser-scanning unit (LSM 700 4× pigtailed laser 405-488-555-639; Zeiss, Jena, Germany) enabled confocal imaging. For excitation, 405, 488, and $639 \mathrm{~nm}$ lasers were used. Fluorescence emission was revealed by Main Dichroic Beam Splitter and Variable Secondary Dichroic Beam Splitter. Triple staining fluorescence images were acquired separately using ZEN 2012 software in the blue, green, and infrared channels at a resolution of $1,024 \times 1,024$ pixels, with the confocal pinhole set to one Airy unit and then saved in TIFF format.

\section{Cell viability assays}

For MTT and Cell-Titer GLO assays, cells were seeded into 96-well microtiter plates (BD Falcon, USA) at the density of $10 \times 10^{3}$ cells/well, whereas for the PI assay, cells were seeded into 48 -well microtiter plates at the density of $50 \times 10^{3}$ cells/ well. After $24 \mathrm{~h}$, the cells were incubated with DNPs at increasing concentrations $(50,100,150$, and $200 \mu \mathrm{g} / \mathrm{mL})$ in triplicate. The assays were performed after $24 \mathrm{~h}$ and $48 \mathrm{~h}$ of incubation, according to the manufacture's instructions. Briefly, for MTT assay, $10 \mu \mathrm{L}$ of a $5 \mathrm{mg} / \mathrm{mL}$ MTT solution in RPMI 1640 medium, no phenol red (Sigma-Aldrich), was added to each well. The plates were then incubated under cell culture conditions for $3 \mathrm{~h}$. Subsequently, $100 \mu \mathrm{L}$ of 
MTT solvent ( $\mathrm{HCl} 0.1 \mathrm{~N}$ in isopropanol) was added to each well and incubated for $1 \mathrm{~h}$ at RT with stirring to dissolve the formazan crystals. Absorbance of each sample was detected by Microplate Reader 680 (Bio-Rad) at 570 nm. For CellTiter GLO, $100 \mu \mathrm{L}$ of Cell-Titer GLO reagent was added to $100 \mu \mathrm{L}$ of medium containing cells and incubated at RT for $10 \mathrm{~min}$ to stabilize luminescent signal. Luminescence was recorded for $0.25 \mathrm{~s}$ per well by Multilabel Reader (PerkinElmer, MA, USA). For PI analysis, cells were washed in PBS and resuspended in $200 \mu \mathrm{L}$ of a solution containing $0.1 \%$ sodium citrate, $0.1 \%$ Triton X-100, and $50 \mu \mathrm{g} / \mathrm{mL}$ PI (SigmaAldrich). Following incubation at $4^{\circ} \mathrm{C}$ for $30 \mathrm{~min}$ in the dark, the cell DNA content was analyzed with a Becton Dickinson FACScan flow cytometer using the Lysis I program and the percentage of cells in the hypodiploid region was calculated. All measurements were carried out in triplicate, in three independent experiments.

\section{Quantitative real-time polymerase chain reaction ( $q R T-P C R)$}

A20 cells $\left(300 \times 10^{3}\right)$ were incubated with DNPs•pA2036• polyArg•siRNABcl 2 and DNPs•pRND•polyArg•siRNA (100 pmol siRNA/200 $\mu \mathrm{g}$ diatomite) for $24 \mathrm{~h}$, collected and washed twice in PBS. Total RNA extraction and qRT-PCR were performed as previously described. ${ }^{35}$ Briefly, RNA aliquots $(1 \mu \mathrm{g})$ were reverse transcribed using Random Examers and Superscript IV Reverse Transcriptase (Thermo Fisher Scientific), according to the manufacturer's protocol. qRT-PCR was carried out with the Quantstudio 7 Flex RealTime PCR system (Thermo Fisher Scientific) and PowerUp SYBR Green Master Mix (Thermo Fisher Scientific) under the following conditions: $50^{\circ} \mathrm{C}, 2 \mathrm{~min} ; 95^{\circ} \mathrm{C}, 2 \mathrm{~min}$; $\left(95^{\circ} \mathrm{C}\right.$, $\left.15 \mathrm{~s} ; 60^{\circ} \mathrm{C}, 60 \mathrm{~s}\right) \times 40$. Primers were as follows: GAPDH, forward 5'-GTCAAGGCCGAGAATGGGAAGC-3' and reverse 5'-AGAAGGGGCGGAGATGATGACC-3' and Bcl2, forward 5'-TCGCAGAGATGTCCAGTCAGC and reverse 5'-CCGGTTCAGGTACTCAGTCATC. Bcl2 expression levels were calculated relative to GAPDH messenger RNA (mRNA) levels as endogenous control and expressed as $\log \Delta C t\left[2^{-(C t \text { sample-Ct } \beta \text {-GAPDH })}\right]$. Standard deviation (SD) was expressed as \% of $C t$ values of three independent experiments.

\section{Western blot analysis}

Cells were treated for $48 \mathrm{~h}$ as described earlier, collected, washed twice in PBS, and resuspended in $20-40 \mu \mathrm{L}$ of radio immunoprecipitation assay (RIPA) buffer $(50 \mathrm{mM}$ Tris- $\mathrm{HCl}$ pH 7.4, 1\% NP40, 0.25\% sodium deoxycholate,
$150 \mathrm{mM} \mathrm{NaCl}, 1 \mu \mathrm{g} / \mathrm{mL}$ aprotinin, leupeptin, pepstatin, $1 \mathrm{mM} \mathrm{Na}_{3} \mathrm{VO}_{4}, 1 \mathrm{mM} \mathrm{NaF}$ ) for $30 \mathrm{~min}$ on ice and centrifuged at $14,000 \times g$ for $30 \mathrm{~min}$ at $4^{\circ} \mathrm{C}$. Protein concentration was determined by a modified Bradford method, using the BioRad protein assay and compared with bovine serum albumin standard curve. ${ }^{36}$ Cytosolic proteins $(10 \mu \mathrm{g})$ were separated by sodium dodecyl sulfate polyacrylamide gel electrophoresis, electrotransferred to nitrocellulose and reacted with Bcl2 monoclonal antibody (Santa Cruz, TX, USA) and GAPDH monoclonal antibody (Cell Signaling, MA, USA). Blots were then developed using enhanced chemiluminescence detection reagents (SuperSignal West Pico, Pierce) and exposed to X-ray film. All films were scanned for densitometric analysis using ImageJ 1.410 software.

\section{Statistical analysis}

Results of the assays are expressed as mean \pm SD of three independent experiments. Data are reported as average and $\mathrm{SD}$. The statistical significance of differences among groups was evaluated using analysis of variance, using the software KaleidaGraph v 4.1. The significance was accepted at the confidence level of $95 \%(P<0.05)$.

\section{Results}

\section{Bare nanoparticle characterization}

In this study, DNPs were used to develop a drug delivery system for active targeting of B-cell lymphoma. The morphology of DNPs deposited on crystalline silicon was investigated by AFM. A representative AFM image and the corresponding height profile are presented in Figure 1A. The analysis highlights the presence of nanoparticles of irregular shape and a mean size of $\sim 200 \mathrm{~nm}$. Size values were confirmed by DLS measurements performed on DNPs dispersed in deionized water ( $\mathrm{pH} 7)$. The results showed an intensity peak corresponding to a size population of $280 \pm 80 \mathrm{~nm}$ (poly dispersion index $=0.1$ ) (Figure $1 \mathrm{~B}$ ). The $\zeta$-potential of the DNPs was $-19 \pm 3 \mathrm{mV}$; the negative charge was most likely due to the presence of silanol groups $(\mathrm{Si}-\mathrm{OH})$ on the surface of nanoparticles after treatment with hot acids. ${ }^{37}$

\section{BCR-mediated uptake of DNPs}

After silanization, DNPs were conjugated, using EDC/NHS chemistry, to an Id-peptide (pA2036) specifically recognized by the Ig-BCR of A20 cells in mice engrafted with A20 lymphoma. ${ }^{38}$ pA2036 was isolated from random peptide libraries as the most effective at targeting the A20 Ig-BCR; random peptide ( $\mathrm{pRND}$ )-conjugated DNPs were used as negative control. ${ }^{29}$ 

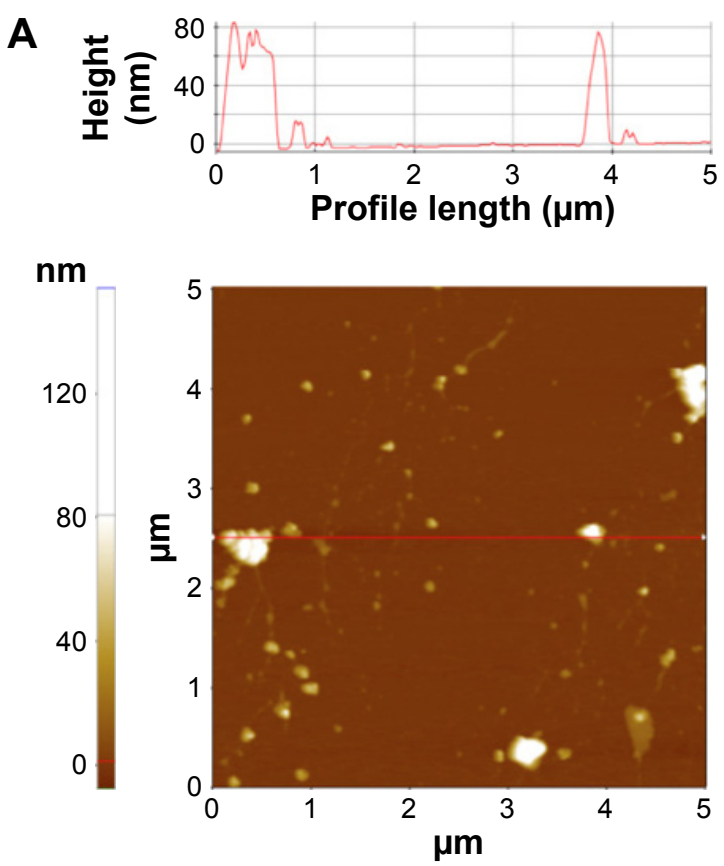

B

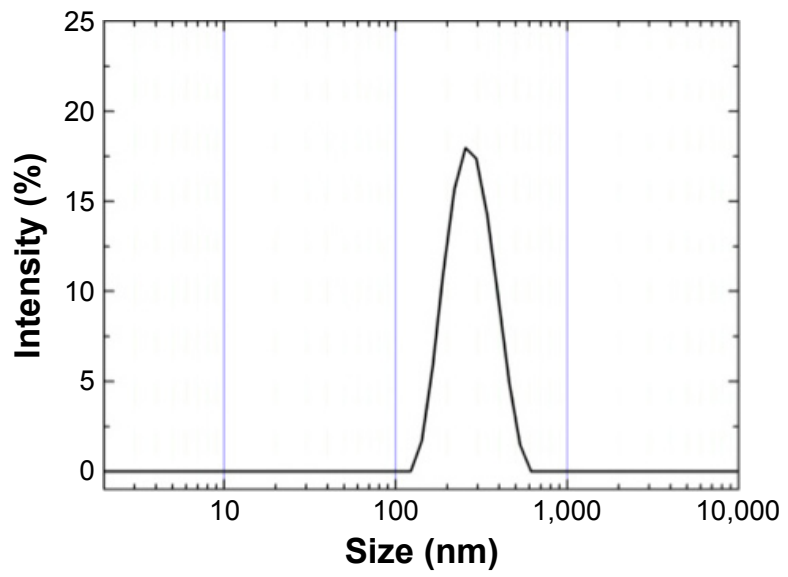

Figure I Characterization of DNPs by AFM and DLS.

Note: (A) AFM image of DNPs deposited on silicon and corresponding height measurement and (B) size distribution of DNPs in water ( $\mathrm{pH}=7$ ), analyzed by DLS Abbreviations: DNPs, diatomite nanoparticles; AFM, atomic force microscopy; DLS, dynamic light scattering.

Particle size distributions determined by DLS after diatomite functionalization with pA2036 and pRND were $390 \pm 20 \mathrm{~nm}$ and $350 \pm 30 \mathrm{~nm}$, respectively, indicating that no particle aggregation had occurred during functionalization. The pA2036- and pRND-conjugated DNPs exhibited $\zeta$-potentials of $-10 \pm 1 \mathrm{mV}$ and $-12 \pm 1 \mathrm{mV}$, respectively.

The uptake of the nanoparticles functionalized with fluorescent (green) pA2036 (DNPs•pA2036*) by A20 cells in vitro was investigated by flow cytometry (Figure 2 ). On the basis of previous investigations, A20 lymphoma cells were incubated with nanoparticles at $50 \mu \mathrm{g} / \mathrm{mL}$ for $2 \mathrm{~h}$ at $37^{\circ} \mathrm{C} . .^{30,39}$ To exclude nonspecific binding of the nanoparticles to the outer surface of the plasma membrane, extracellular fluorescence was quenched using Trypan blue. ${ }^{40}$ The results of flow cytometric analysis indicated a fluorescent cell population of $95.5 \% \pm 3 \%$ in non-permeabilized cells (Figure 2B) and $96 \% \pm 4 \%$ in mildly permeabilized cells (Figure $2 \mathrm{E}$ ). To verify that the uptake of nanoparticles was mediated via the Ig-BCR, the same experiment was performed using nanoparticles functionalized with a fluorescent nonspecific peptide (DNPs•pRND*); the resulting fluorescence was $36 \% \pm 3 \%$ in non-permeabilized and $39 \% \pm 4 \%$ in mildly permeabilized cells (Figure 2C and F). In this case, the limited uptake was not due to receptor-mediated endocytosis, but more likely to caveolae-dependent endocytosis, which occurs when anionic nanoparticles interact with positive sites on membrane proteins. ${ }^{41,42}$ To further confirm the specificity of pA2036-modified DNPs in targeting A20 cells, the nanoparticle uptake of A20 cells was compared with that of 5T33MM cells, a surface IgG-positive B-cell line unable to bind the pA2036 peptide (Figure 2H). ${ }^{29}$ The fluorescent cell population of mildly permeabilized 5T33MM cells treated with DNPs•pA2036* was approximately threefold lower than that of A20 cells ( $34 \% \pm 3 \%$ vs $96 \% \pm 4 \%$ ). These data, together with that obtained using DNPs•pRND*, indicate that a portion of DNPs•pA2036* nanoparticles were nonspecifically internalized by the cells.

Cellular uptake of DNPs•pA2036* was also investigated by confocal fluorescence microscopy. Plasma membranes and nuclei of A20 cells were labeled with CellMask Deep Red and NucBlue, respectively, and analysis of cellular internalization was carried out using three different incubation times (30, 60, and $120 \mathrm{~min})$. Figure 3 shows representative confocal microscopy images of cells treated with DNPs•pA2036* after 60 min of incubation, recorded at different focal depths along the $z$-axis. The endocytosed nanoparticles appear as punctate small vesicles distributed in the cytoplasm. This spot-like intracellular distribution confirms an endocytic mechanism for the uptake of DNPs within vesicular structures. An intracellular structure, containing a large amount of DNPs, was also visible. ${ }^{43}$ Figure $3 \mathrm{~F}$ shows orthogonal projections of z-stack acquisition, illustrating the 


\section{A}

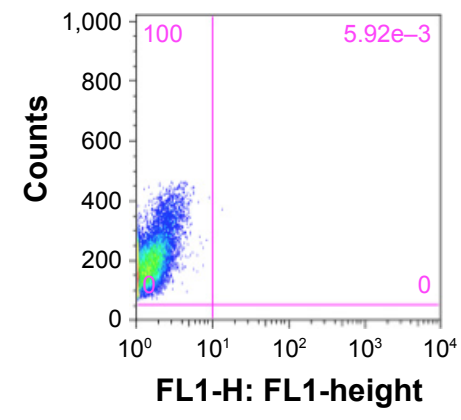

E

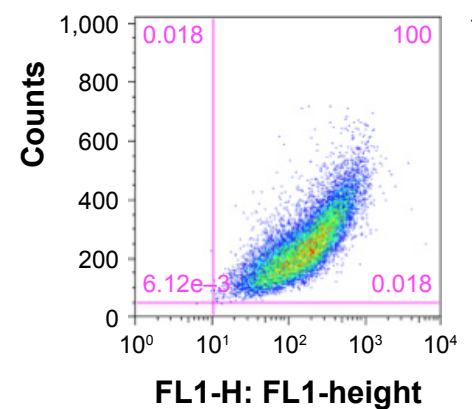

B

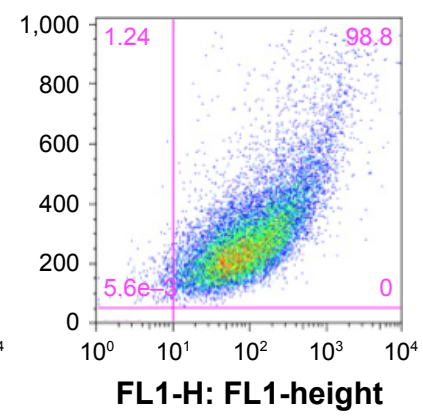

F

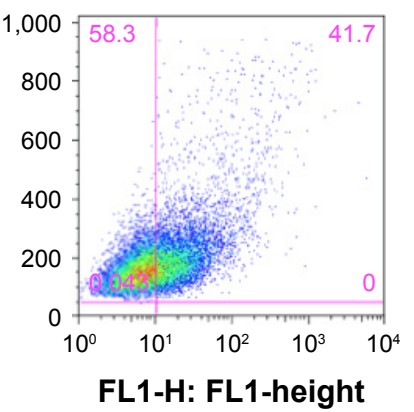

C

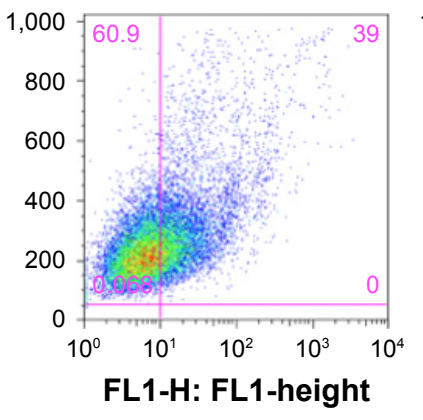

G

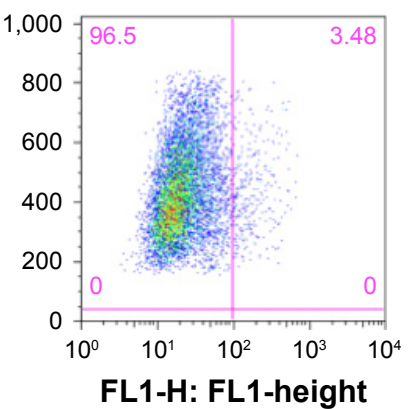

D

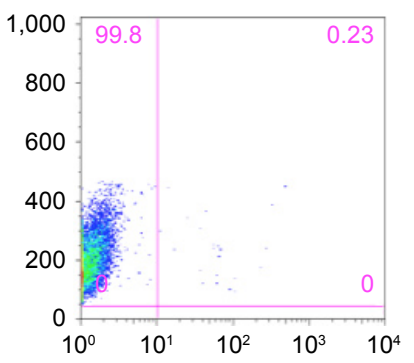

FL1-H: FL1-height

H

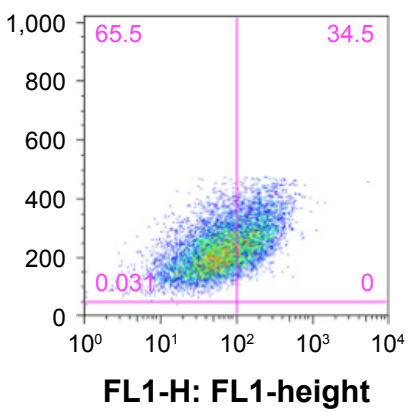

Figure 2 FACS analysis of A20 and 5T33MM cells treated with nanoparticles.

Notes: Representative image obtained using non-permeabilized A20 cells (A-C), mildly permeabilized A20 cells (D-F), and mildly permeabilized 5T33MM cells (G, H). (A, D) Untreated A20 cells; (B, E) DNPs•pA2036*-treated A20 cells; (C, F) DNPs•pRND*-treated A20 cells; (G) untreated 5T33MM cells; (H) DNPs•pA2036*-treated 5T33MM cells.

Abbreviations: FACS, fluorescence-activated cell sorting; 5T33MM, 5T33 murine myeloma; DNPs, diatomite nanoparticles; FL, fluorescence.
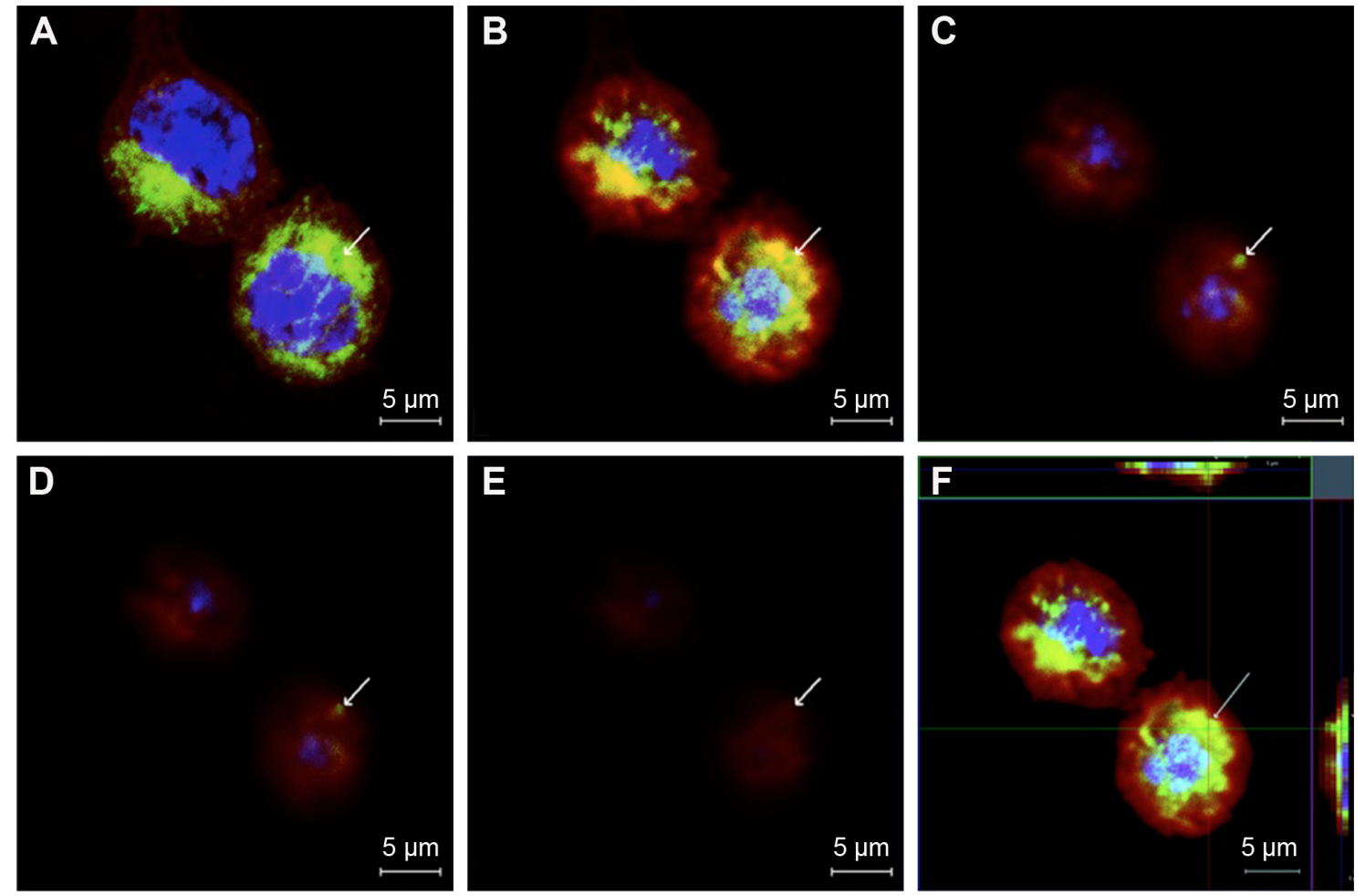

Figure 3 Confocal microscopy analysis of DNPs•pA2036*-treated A20 cells.

Notes: (A-E) Gallery of merged images acquired along the z-axis of triple immunofluorescence-stained A20 cells. Cell nuclei and membranes were stained with Hoechst 33342 (NucBlue) and CellMask Deep Red, respectively. DNPs•pA2036* is visible as green color. White arrow indicates intracellular structures containing a large amount of DNPs•pA2036*. (F) Orthogonal projections of z-stack acquisitions showing that vesicles and large endocytic structures were indeed present inside the cell. Scale bars correspond to $5 \mu \mathrm{m}$.

Abbreviation: DNPs, diatomite nanoparticles. 
large DNP-containing area and the small vesicles detected inside the cells.

\section{Targeted siRNA delivery}

To further explore the potential of DNPs for application in targeted drug delivery, their ability to vehiculate siRNA into lymphoma cells was investigated. To this end, DNPs were conjugated with pA2036 engineered with a C-terminal stretch of basic amino acids (arginine residues) to promote the formation of siRNA-peptide complexes based on electrostatic interactions; addition of these amino acids also protects the nucleic acid from enzymatic degradation. ${ }^{17}$ This approach, illustrated in Figure 4A, was based on the concept that a single molecule could simultaneously load the siRNA and facilitate active targeting by specific Ig-BCR recognition. The mean particle size of DNPs modified in this way, determined by DLS, was $370 \pm 20 \mathrm{~nm}$ with a negative $\zeta$-potential of $-35 \pm 1 \mathrm{mV}$. The internalization of the complex formed by DNPs, pA2036-9R, and red fluorescent siRNA (DNPs•pA2036-9R•siRNA*) was evaluated by flow cytometry. The result indicated that $58.7 \% \pm 2 \%$ of non-permeabilized and $52.2 \% \pm 3 \%$ of mildly permeabilized cells internalized fluorescent DNPs
(Figure 4B). The comparatively lower value of internalization relative to DNPs•pA2036* was probably due to the presence of the poly-arginine-siRNA complex at the C-terminus of pA2036 masking the specific recognition sequence of the A2036 peptide, thus reducing the efficiency of its interaction with Ig-BCR. Use of the pRND control (DNPs•pRND9R・siRNA*; $350 \pm 40 \mathrm{~nm}, \zeta$-potential of $-39 \pm 1 \mathrm{mV}$ ) resulted in fluorescence values of $37.8 \% \pm 2.5 \%$ and $35 \% \pm 3.5 \%$ in non-permeabilized and mildly permeabilized cells, respectively (Figure 4B). These data indicate that a limited amount of nonspecific cellular uptake occurred.

To enhance the internalization efficiency and attempt to minimize the influence of nonspecific DNPs uptake, optimization of the surface functionalization was performed. Nanoparticles were conjugated with both the original pA2036 sequence and a poly-Arg peptide complexed to the siRNA molecule (DNPs•pA2036•polyArg•siRNA*). This strategy, depicted in Figure 4C, allowed 1) immobilization of an unmodified pA2036 on the diatomite surface, which should be more efficiently recognized by the Ig-BCR compared to the molecule containing the poly-Arg stretch, and 2) immobilization of the pA2036 and siRNA on different sites of the particle, increasing the accessibility in targeting the Ig-BCR.
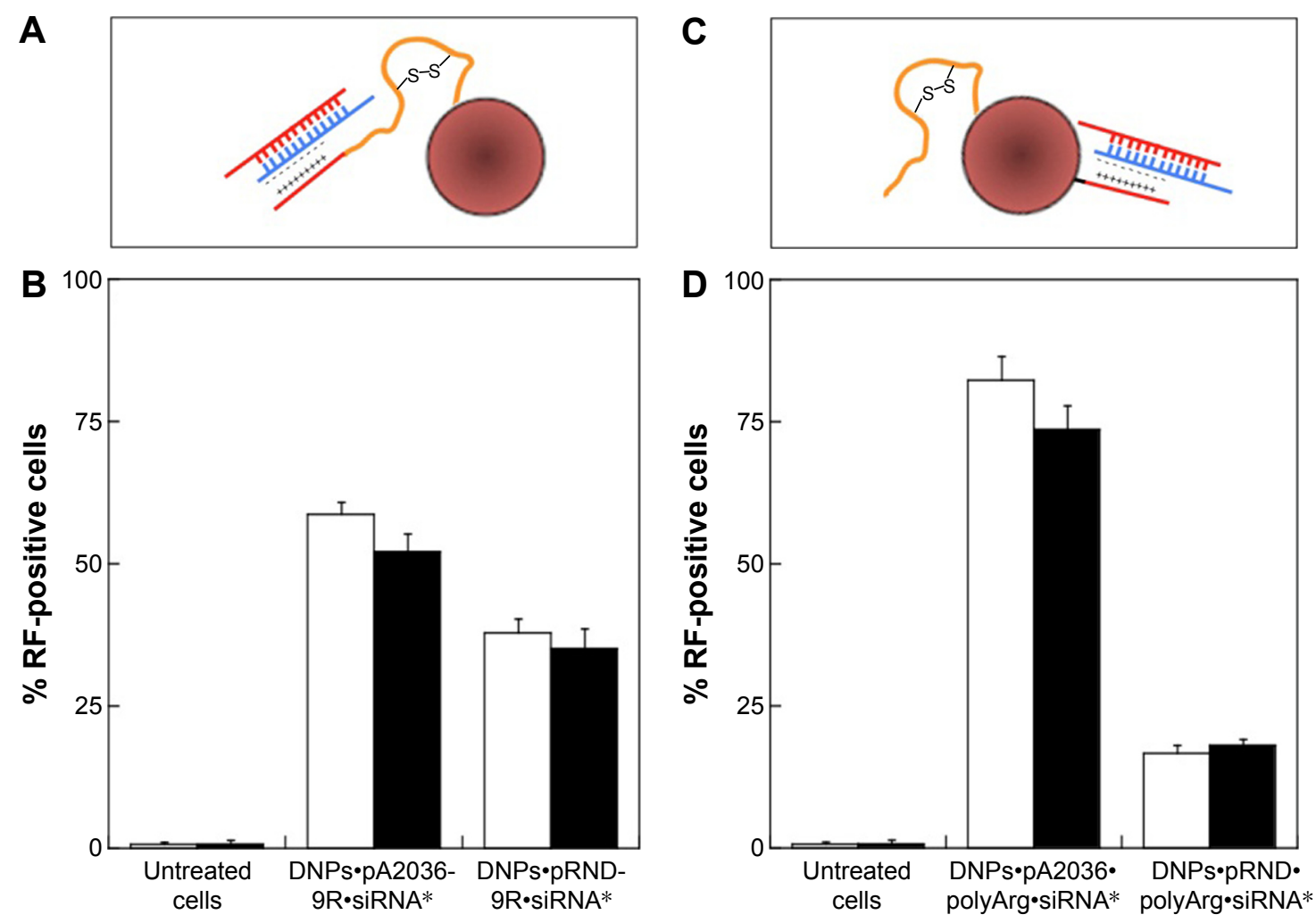

Figure 4 DNP functionalization strategies and FACS analysis.

Notes: (A, C) Schematic representation of two different diatomite functionalization approaches. (B, D) Flow cytometric analysis on non-permeabilized (white columns) and mildly permeabilized (black columns) A20 cells. (B) DNPs•pA2036-9R•siRNA*- and DNPs•pRND-9R・siRNA*-treated cells, (D) DNPs•pA2036•polyArg•siRNA*- and DNPs•pRND•polyArg•siRNA*-treated cells.

Abbreviations: FACS, fluorescence-activated cell sorting; DNPs, diatomite nanoparticles; siRNA, small interfering RNA; RF, red fluorescence. 

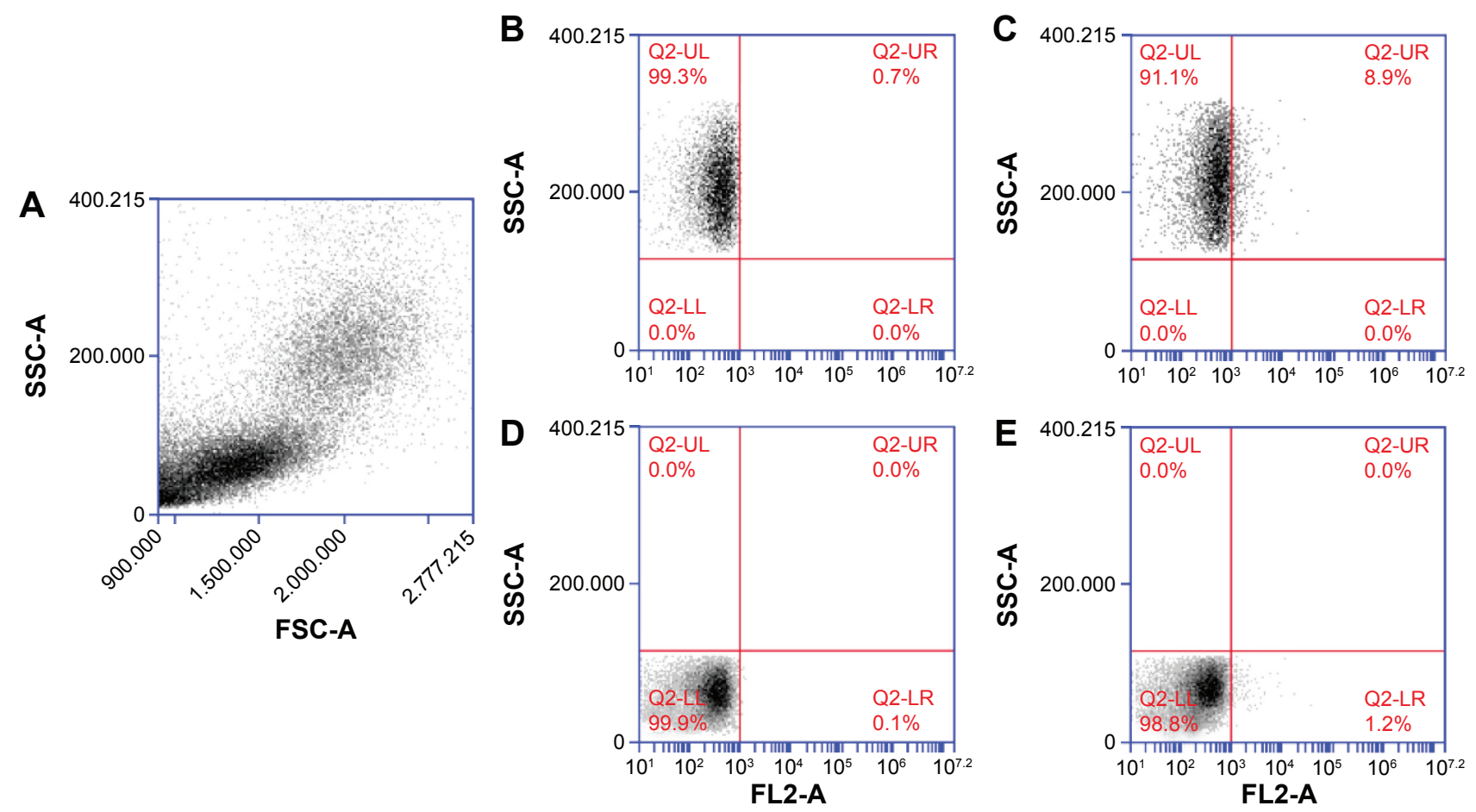

Figure 5 Representative images of FACS analysis on PBMCs treated with DNPs•pA2036•polyArg•siRNA*.

Notes: (A) Physical parameters, (B, C) flow cytometry images of non-treated and treated monocytes, respectively and (D, E) flow cytometry images of non-treated and treated lymphocytes, respectively.

Abbreviations: FACS, fluorescence-activated cell sorting; PBMCs, peripheral blood mononuclear cells; DNPs, diatomite nanoparticles; siRNA, small interfering RNA; FSC, forward scatter; SSC, side scatter; FL, fluorescence.

Following these functionalization steps, the nanoparticles exhibited an increase in size to $400 \pm 40 \mathrm{~nm}$ and in $\zeta$-potential to $-11 \pm 1 \mathrm{mV}$. Figure 4D shows that, when A20 cells were treated with DNPs•pA2036•polyArg•siRNA*, the fluorescent cell populations were $82.4 \% \pm 4 \%$ (non-permeabilized) and $73.8 \% \pm 3.8 \%$ (mildly permeabilized). In contrast, when A20 cells were incubated with DNPs•pRND•polyArg•siRNA* $(390 \pm 40 \mathrm{~nm}, \zeta$-potential $=-12 \pm 1 \mathrm{mV})$, the fluorescent cell populations comprised $16.7 \% \pm 1.5 \%$ and $18 \% \pm 1 \%$ of non-permeabilized and mildly permeabilized cells, respectively.

The internalization efficiency of DNPs•pA2036• polyArg•siRNA* was also evaluated in a normal cell population (PBMCs). Compared to untreated cells, the fluorescent lymphocytic population was of $1.9 \% \pm 0.7 \%$, whereas monocytic population resulted in $9.3 \% \pm 0.8 \%$ (Figure 5).

The size and surface charge of nanoparticles are represented in Figure 6. This result highlights the efficiency of the functionalization strategy, since a significant increase in ligandmediated targeting was observed along with reduced nonspecific internalization of DNPs•pRND•polyArg•siRNA*.

The observed differences in internalization efficiency were likely due to the variation in the size and $\zeta$-potential

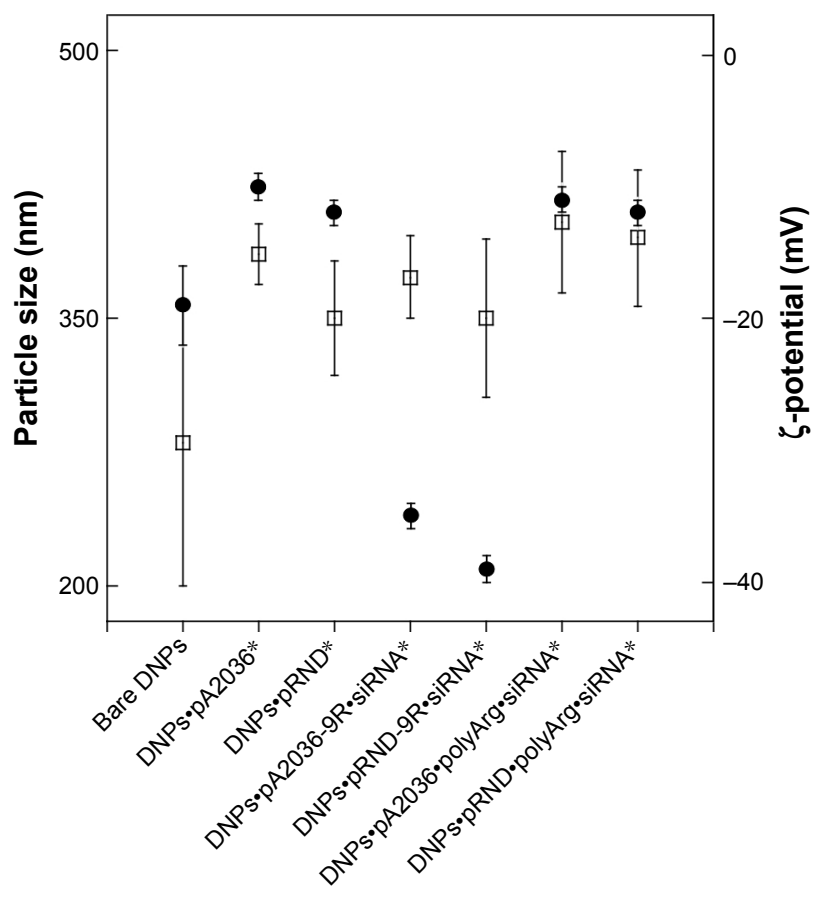

Figure 6 Characterization of the size and surface charge of DNPs.

Notes: Size $(\square)$ and $\zeta$-potential $(\bullet)$ of bare DNPs, DNPs•pA2036*, DNPs•pA20369R・siRNA* and DNPs•pA2036•polyArg•siRNA* determined by DLS at RT. Reported values are the mean of three independent measurements \pm SD.

Abbreviations: DNPs, diatomite nanoparticles; siRNA, small interfering RNA; DLS, dynamic light scattering; RT, room temperature; SD, standard deviation. 
Table I DNPs size, surface charge, and internalization efficiency

\begin{tabular}{|c|c|c|c|c|}
\hline \multirow[t]{2}{*}{ Samples } & \multirow{2}{*}{$\begin{array}{l}\text { Size } \pm \text { SD } \\
(\mathrm{nm})\end{array}$} & \multirow{2}{*}{$\begin{array}{l}\zeta \text {-potential } \pm \text { SD } \\
(\mathrm{mV})\end{array}$} & \multicolumn{2}{|c|}{ A20 cell uptake \pm SD (\%) } \\
\hline & & & $\overline{n p}$ & $\mathbf{m p}$ \\
\hline DNPs•pA2036-9R・siRNA* & $370 \pm 20$ & $-35 \pm 1$ & $59 \pm 2$ & $52 \pm 3$ \\
\hline DNPs•pRND-9R・siRNA* & $350 \pm 40$ & $-39 \pm 1$ & $38 \pm 2$ & $35 \pm 3$ \\
\hline DNPs•pA2036•polyArg•siRNA* & $400 \pm 40$ & $-I I \pm I$ & $82 \pm 4$ & $74 \pm 4$ \\
\hline DNPs•pRND•polyArg•siRNA* & $390 \pm 40$ & $-|2 \pm|$ & $17 \pm 1$ & $18 \pm 1$ \\
\hline
\end{tabular}

Abbreviations: DNPs, diatomite nanoparticles; SD, standard deviation; np, non-permeabilized; mp, mildly permeabilized; siRNA, small interfering RNA.

of nanoparticles (Table 1). These data confirm that caveolae-dependent endocytosis, which occurs during passive targeting, is influenced by the size and surface charge of nanovectors. ${ }^{42}$

\section{Cell viability}

To assess A20 cell viability following DNP exposure, MTT, Cell-Titer GLO, and PI assays were performed ${ }^{44}$ A20 cells were incubated in the presence of DNPs functionalized with pA2036 and with a poly-Arg complexed to a nontargeting siRNA (DNPs•pA2036•polyArg•siRNASCR) at four different concentrations $(50,100,150$, and $200 \mu \mathrm{g} / \mathrm{mL})$ for 24, 48, and $72 \mathrm{~h}$ (Figure 7A-C, respectively). The choice of the incubation period reflects the fact that the uptake was relatively rapid and had already occurred after $2 \mathrm{~h}$; therefore, toxicity would be expected to be observed within $24 \mathrm{~h} .{ }^{45} \mathrm{In}$ addition, the doses of tested DNPs were chosen as similar to those resulting in good tolerance when injected intravenously in nude mice. ${ }^{46,47}$ The results showed no differences in cell death in treated cells compared with untreated control cells. Cell viability was also analyzed by light microscopy after $48 \mathrm{~h}$ of incubation of A20 cells in the presence of DNPs, and no effects on cell morphology were observed (Insets 1 and 2, Figure 7B). The cytotoxic effect of modified DNPs was also measured by MTT assay using human PBMCs (Figure 7D). Together, these results demonstrate that no significant signs of cellular toxicity were observed as a result of nanoparticle treatment, even after an extended period of time.

\section{Targeted gene silencing of $\mathrm{Bcl} 2$ using DNPs•pA2036•polyArg•siRNABcl2}

The downregulation of $\mathrm{Bcl} 2$ represents a promising potential therapeutic approach in cancer therapy, particularly in hematological malignancies, since its application can enhance the effects of chemotherapeutic agents. ${ }^{48-50}$ Previously reported pattern of siRNA release from diatomite demonstrated an initial phase with a burst trend within $12 \mathrm{~h}$; therefore, $B c l 2$ gene silencing was determined by
qRT-PCR $24 \mathrm{~h}$ after treatment of cells in the presence of $200 \mu \mathrm{g} / \mathrm{mL}$ DNPs functionalized with pA2036 and a polyArg peptide complexed to siRNA directed against $\mathrm{Bcl} 2$ mRNA (DNPs•pA2036•polyArg•siRNABcl2). ${ }^{17}$ As depicted in Figure 8A, DNPs•pA2036•polyArg•siRNABcl2 caused a $40.90 \% \pm 4.5 \%$ decrease in the levels of $B c l 2$ mRNA, whereas only a slight reduction in $B c l 2$ mRNA expression levels was observed after treatment of cells with the control peptide, DNPs•pRND•polyArg•siRNABcl2 (9.09\% $\pm 9.70 \%)$, relative to untreated cells (negative control). These results were compared to those obtained by transfecting A20 cells using a conventional method (lipofectamine); with respect to basal expression, siRNABcl2 (100 pmol) was able to downregulate the mRNA level by $\sim 10 \%$ after $24 \mathrm{~h}$ after transfection (data not shown), demonstrating that treatment of A20 cells with DNPs•pA2036•polyArg•siRNABcl 2 resulted in more efficient silencing relative to the results achieved using lipofectamine. Thus, DNPs•pA2036•polyArg•siRNABcl2 could be efficiently and specifically delivered into A20 cells, resulting in significant gene silencing.

The knockdown results were confirmed by Western blot analysis (Figure 8B, upper panel). Compared with untreated cells, $48 \mathrm{~h}$ of treatment with DNPs•pA2036•polyArg• siRNABcl2 reduced Bcl2 expression by $45.10 \% \pm 8.10 \%$, whereas treatment with DNPs•pRND•polyArg $\bullet$ siRNABcl2 resulted in a decrease in $\mathrm{Bcl} 2$ protein expression of $7.10 \% \pm 5.10 \%$, as determined by densitometric analysis of the intensity of the bands (Figure $8 \mathrm{~B}$, lower panel). These results suggest that the reduction in $\mathrm{Bcl} 2$ expression was due to the function of siRNABcl2, successfully delivered into the cytoplasm by DNPs.

\section{Discussion}

A characteristic failure in the treatment of lymphoma is the inability of traditional therapies to reach the anatomic homing of tumorigenic B cells. Effective intracellular drug delivery to target cells is undoubtedly the most difficult hurdle to overcome in the development of a therapy. 

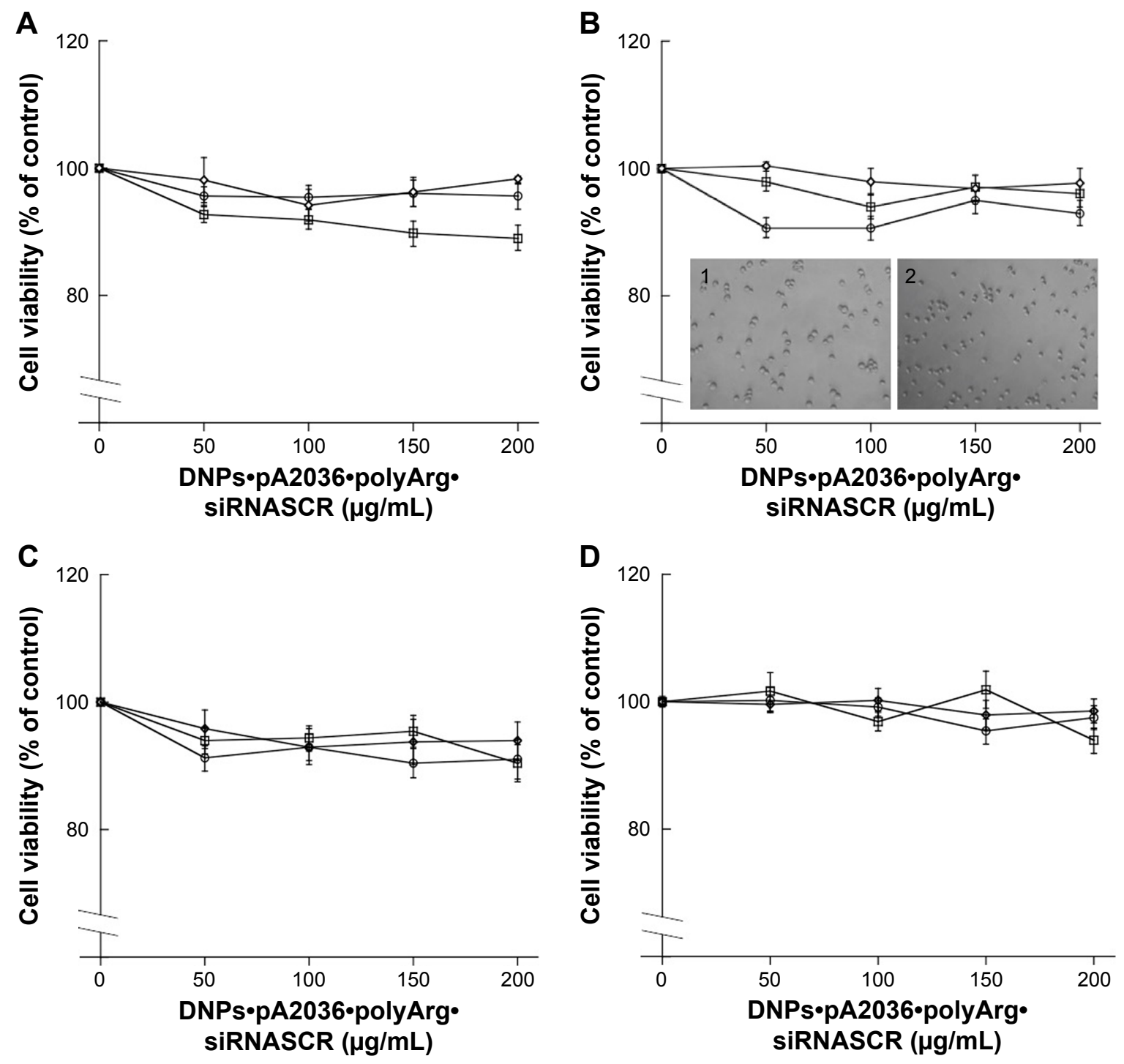

Figure 7 Cytotoxicity assays.

Notes: Cell viability assays (Cell-Titer GLO $\square$, MTT O and PI $\diamond)$ of A20 cells treated for (A) $24 \mathrm{~h}$, (B) $48 \mathrm{~h}$ and (C) $72 \mathrm{~h}$ with DNPs•pA2036•polyArg•siRNASCR. (D) MTT cell viability assay of PBMCs after $24 \mathrm{~h}(\square), 48 \mathrm{~h}(O)$, and $72 \mathrm{~h}(\diamond)$ of treatment with DNPs•pA2036•polyArg•siRNASCR. Reported values are the mean of three independent measurements \pm SD. Insets: (B) Light microscopy image of A20 cell before (I) and after (2) treatment with DNPs•pA2036•polyArg•siRNASCR (I50 $\mu g / \mathrm{mL})$.

Abbreviations: MTT, 3-(4,5-dimethythiazol-2-yl)-2,5-diphenyl tetrazolium bromide; PI, propidium iodide; DNPs, diatomite nanoparticles; siRNA, small interfering RNA; PBMCs, peripheral blood mononuclear cells; SD, standard deviation.

The hypervariable regions of the surface Ig-BCR expressed by lymphoma cells are products of the rearrangement of the immunoglobulin genes and are unique to each clonal B-cell population. Hence, the idiotypic determinants of the Ig-BCR expressed by lymphoma cells represent a specific tumor antigen. Ig-BCR was explored in this study because of its potential for use in the development of active personalized targeting therapy.

The A2036 Id-peptide, previously selected by phage display libraries, was chosen since it does not bind to normal mouse PBMCs and bone marrow cells, other B-cell tumor cell lines (MC3, Raji, 5T33MM) or TT cell lines (HPBALL, Jurkat) but is recognized only by A20 lymphoma cells via their Ig-BCR. ${ }^{29}$ As a ligand of the idiotypic determinants of the Ig-BCR, the specificity of each Id-peptide is strongly restricted to a specific B-cell clone (normal or neoplastic) that harbors the cognate Ig-BCR.

In the context of this novel ligand-mediated targeting system, DNPs were conjugated with pA2036, and their ability to undergo cell-specific internalization was evaluated by cytofluorimetric analysis and confocal microscopy. The results demonstrated efficient internalization of nanoparticles. In addition, comparison with data obtained using nanoparticles conjugated with a random peptide or by treatment of a myeloma cell line (5T33MM) highlighted that a small fraction of nanoparticles underwent nonspecific cell 
A

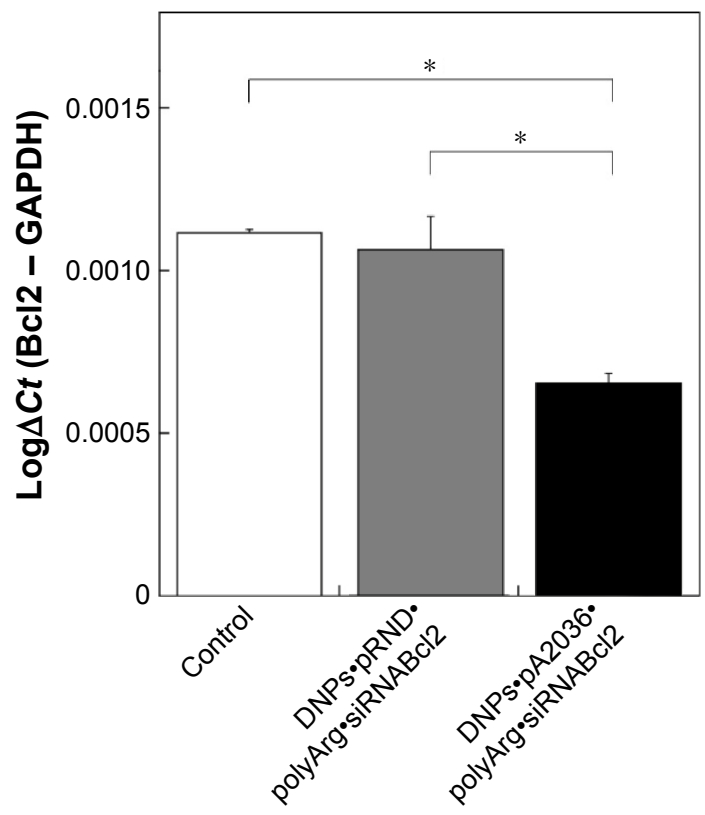

B
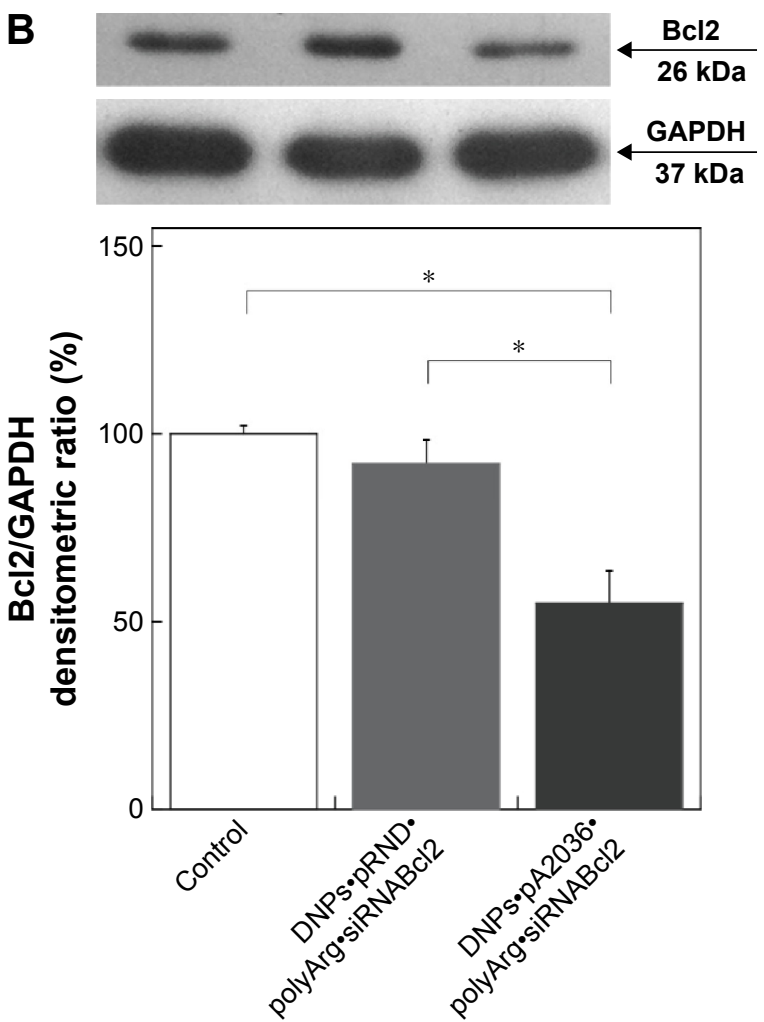

Figure 8 Bcl2 mRNA knockdown.

Notes: (A) Effect of DNPs•pA2036•polyArg•siRNABcl2 and DNPs•pRND•polyArg•siRNABcl2 on Bcl2 mRNA expression levels, determined by quantitative PCR. (B) Effect of DNPs•pA2036•polyArg•siRNABcl2 and DNPs•pRND•polyArg•siRNABcl2 on downregulation of Bcl2 protein expression levels determined by Western blot. In both experiments, gene expression values are mean $( \pm S D)$ of three biological replicates. Significant differences relative to controls were evaluated using $A N O V A$. $* P<0.05$.

Abbreviations: Bcl2, B-cell lymphoma/leukemia 2; mRNA, messenger RNA; DNPs, diatomite nanoparticles; siRNA, small interfering RNA; PCR, polymerase chain reaction; $\mathrm{SD}$, standard deviation; ANOVA, analysis of variance.

uptake. This result indicates that, in addition to receptormediated endocytosis, nanoparticles were taken up by a limited, alternative, nonspecific mechanism, which was probably caveolae-dependent. ${ }^{41}$

Cytofluorimetric analysis was also performed using siRNA-loaded pA2036-nanoparticles. Two different types of nanoparticles were employed: 1) nanoparticles conjugated with the A2036 sequence engineered with nine arginine residues at the $\mathrm{C}$-terminus, which, besides containing the sequence for selective recognition of $\mathrm{B}$ cells, were also able to form a stable electrostatic complex with negatively charged siRNA; and 2) nanoparticles conjugated with both an unmodified pA2036 and a poly-Arg complexed with siRNA. The results demonstrate that the former functionalization strategy was less efficient, probably due to the presence of the conjugated arginine residues masking the specific recognition sequence of the A2036 peptide and thus reducing the efficiency of its interaction with the Ig-BCR. Furthermore, the latter functionalization strategy resulted in both an increase in specific uptake and a decrease in nonspecific internalization, probably due to the altered surface charge of the nanovector..$^{42}$ In addition, the internalization of the so modified nanoparticles was also analyzed on PBMCs resulting in a very low nonspecific uptake.

The toxicity of the nanoparticles modified with the Idpeptide and siRNA to both A20 cells and human PBMCs from healthy donors was tested using cell viability assays. The resulting data demonstrated no significant effects on cell viability after nanoparticle treatment.

Given their high specific internalization efficiency and lack of cytotoxicity, pA2036-modified diatomite particles were used to deliver siRNA direct against the mRNA of the antiapoptotic factor Bcl 2 in A20 cells. qRT-PCR and Western blot analyses indicated effective downregulation of $\mathrm{Bcl} 2$ protein expression when diatomite served as siRNA carrier. These results demonstrated that, once endocytosed by the cell, diatomite successfully released biologically active siRNA into the cytoplasm; however, further studies are required to evaluate the efficiency of gene silencing in vivo, since previous studies have reported discordant results. ${ }^{51,52}$

Delivery of siRNABcl 2 complexed with A2036 peptide has previously been reported to result in a similar silencing 
efficiency; therefore, the use of diatomite as a carrier could allow specific co-delivery of nucleic acids and conventional drugs, a promising combination reported to be capable of increasing the sensitivity of malignant cells to chemotherapeutic agents in cancer treatment. ${ }^{30,50,53,54}$

The strategy presented here represents a highly promising approach for RNAi therapeutic applications in lymphoma treatment. Although the Id-peptide method requires a prior selection procedure for each individual B-cell clone (patient), this does not negate the significance of this work, which provides a proof-of-concept for specific delivery of siRNA cargo into target cells. In addition, this approach could also be applied in the follow-up of cancer patients, using nanoparticles modified with novel imaging agents.

\section{Conclusion}

A novel drug delivery strategy for personalized lymphoma therapy, based on DNPs conjugated with an Id-peptide specifically targeting malignant B cells, was developed in this study. Specific internalization was demonstrated in vitro by flow cytometry and confocal microscopy. Cytotoxicity tests demonstrated that diatomite concentrations ranging from 50 to $200 \mu \mathrm{g} / \mathrm{mL}$ have a negligible influence on cell viability. Furthermore, when the siRNA targeting $B c l 2$ was loaded on to modified DNPs, a significant in vitro downregulation of the target protein was observed. Further research to develop nanoparticles loaded with different anticancer molecules with the potential to work synergistically, and on their applications in vivo, is required.

\section{Acknowledgments}

The authors thank Ivo Rendina for helpful suggestions and critical reading and Luca De Stefano for support. The authors also thank Camillo Palmieri and Deref S.p.A for kindly providing Id-peptide and diatomite earth sample, respectively. This work was supported by funds from Programmi di Ricerca Scientifica di Rilevante Interesse Nazionale (2012CK5RPF_004) and POR Campania FSE 2007-2013, Project CRÈME.

\section{Disclosure}

The authors report no conflicts of interest in this work.

\section{References}

1. Bangham AD, Standish MM, Watkinsal JC. Diffusion of univalent ions across the lamellae of swollen phospholipids. J Mol Biol. 1965; 13(1):238-252.

2. LaVan DA, McGuire T, Langer R. Small-scale systems for in vivo drug delivery. Nat Biotechnol. 2003;21(10):1184-1191.
3. Langer R. New methods of drug delivery. Science. 1990;249(4976): 1527-1533.

4. Shi JJ, Xiao Z, Kamaly N, Farokhzad OC. Self-assembled targeted nanoparticles: evolution of technologies and bench to bedside translation. Acc Chem Res. 2011;44(10):1123-1134.

5. Yang Y, Yu C. Advances in silica based nanoparticles for targeted cancer therapy. Nanomedicine. 2016;12(2):317-332.

6. Schleich N, Po C, Jacobs D, et al. Comparison of active, passive and magnetic targeting to tumors of multifunctional paclitaxel/SPIO-loaded nanoparticles for tumor imaging and therapy. J Control Release. 2014; 194:82-91.

7. Mitra S, Gaur U, Ghosh PC, Maitra AN. Tumour targeted delivery of encapsulated dextran-doxorubicin conjugate using chitosan nanoparticles as carrier. J Control Release. 2001;74(1-3):317-323.

8. Steichen SD, Caldorera-Moore M, Peppas NA. A review of current nanoparticle and targeting moieties for the delivery of cancer therapeutics. Eur J Pharm Sci. 2013;48(3):416-427.

9. Wang X, Li S, Shi Y, et al. The development of site-specific drug delivery nanocarriers based on receptor mediation. J Control Release. 2014;193:139-153.

10. Thomsen LB, Thomsen MS, Moos T. Targeted drug delivery to the brain using magnetic nanoparticles. Ther Deliv. 2015;6(10):1145-1155.

11. Xiong L, Bi J, Tang Y, Qiao SZ. Magnetic core-shell silica nanoparticles with large radial mesopores for siRNA delivery. Small. 2016;12(34): 4735-4742.

12. Davis ME, Zuckerman JE, Choi CH, et al. Evidence of RNAi in humans from systemically administered siRNA via targeted nanoparticles. Nature. 2010;464(7291):1067-1070.

13. Varshosaz J, Farzan M. Nanoparticles for targeted delivery of therapeutics and small interfering RNAs in hepatocellular carcinoma. World J Gastroenterol. 2015;21(42):12022-12041.

14. Barreto JA, O’ Malley W, Kubeil M, Graham B, Stephan H, Spiccia L. Nanomaterials: applications in cancer imaging and therapy. Adv Mater. 2011;23(12):H18-H40.

15. Argyo C, Weiss V, Bräuchle C, Bein T. Multifunctional mesoporous silica nanoparticles as a universal platform for drug delivery. Chem Mater. 2014;26(1):435-451.

16. Vivero-Escoto JL, Slowing II, Trewyn BG, Lin VS. Mesoporous silica nanoparticles for intracellular controlled drug delivery. Small. 2010; 6(18):1952-1967.

17. Rea I, Martucci NM, De Stefano L, et al. Diatomite biosilica nanocarriers for siRNA transport inside cancer cells. Biochim Biophys Acta. 2014;1840(12):3393-3403.

18. Ruggiero I, Terracciano M, Martucci NM, et al. Diatomite silica nanoparticles for drug delivery. Nanoscale Res Lett. 2014;9(1):329-335.

19. Terracciano M, Shahbazi MA, Correia A, et al. Surface bioengineering of diatomite based nanovectors for efficient intracellular uptake and drug delivery. Nanoscale. 2015;7(47):20063-20074.

20. Zhang H, Shahbazi MA, Mäkilä EM, et al. Diatom silica microparticles for sustained release and permeation enhancement following oral delivery of prednisone and mesalamine. Biomaterials. 2013;34(36): 9210-9219.

21. Migkou M, Dimopoulos MA, Gavriatopoulou M, Terpos E. Applications of monoclonal antibodies for the treatment of hematological malignancies. Expert Opin Biol Ther. 2009;9(2):207-220.

22. Reed JC. Bcl-2-family proteins and hematologic malignancies: history and future prospects. Blood. 2008;111(7):3322-3330.

23. Chanan-Khan A. Bcl-2 antisense therapy in B-cell malignancies. Blood Rev. 2005;19(4):213-221.

24. Abdullah LN, Chow EK-H. Mechanisms of chemoresistance in cancer stem cells. Clin Transl Med. 2013;2(1):3-11.

25. Banerjee A, Qian P, Wu Z-S, et al. Artemin stimulates radio- and chemo-resistance by promoting TWIST1-BCL-2-dependent cancer stem cell like behavior in mammary carcinoma cells. J Biol Chem. 2012; 287(51):42502-42515.

26. Ebrahim AS, Sabbagh H, Liddane A, Raufi A, Kandouz M, Al-Katib A. Hematologic malignancies: newer strategies to counter the BCL-2 protein. J Cancer Res Clin Oncol. 2016;142(9):2013-2022. 
27. O’ Brien S, Moore JO, Boyd TE, et al. Randomized phase III trial of fludarabine plus cyclophosphamide with or without oblimersen sodium (Bcl-2 antisense) in patients with relapsed or refractory chronic lymphocytic leukemia. J Clin Oncol. 2007;25(9):1114-1120.

28. Cotter FE, Waters J, Cunningham D. Human Bcl-2 antisense therapy for lymphomas. Biochim Biophys Acta. 1999;1489(1):97-106.

29. Palmieri C, Falcone $\mathrm{C}$, Iaccino $\mathrm{E}$, et al. In vivo targeting and growth inhibition of the A20 murine B-cell lymphoma by an idiotype-specific peptide binder. Blood. 2010;116(2):226-238.

30. Migliaccio N, Palmieri C, Ruggiero I, et al. B-cell receptor-guided delivery of peptide-siRNA complex for B-cell lymphoma therapy. Cancer Cell Int. 2015;15:50-58.

31. Wang Y, Huang HY, Yang L, Zhang Z, Ji H. Cetuximab-modified mesoporous silica nano-medicine specifically targets EGFR-mutant lung cancer and overcomes drug resistance. Sci Rep. 2016;6:25468-25477.

32. De Stefano L, Oliviero G, Amato J, et al. Aminosilane functionalizations of mesoporous oxidized silicon for oligonucleotide synthesis and detection. J R Soc Interface. 2013;10(83):20130160.

33. Terracciano M, Rea I, Politi J, De Stefano L. Optical characterization of aminosilane-modified silicon dioxide surface for biosensing. J Eur Opt Soc Rapid Publ. 2013;8:1303.

34. Kim KJ, Kanellopoulos-Langevin C, Merwin RM, Sachs DH, Asofsky R. Establishment and characterization of BALB/c lymphoma lines with B cell properties. J Immunol. 1979;122(2):549-554.

35. Spatuzza C, Schiavone M, Di Salle E, et al. Physical and functional characterization of the genetic locus of IBtk, an inhibitor of Bruton's tyrosine kinase: evidence for three protein isoforms of IBtk. Nucleic Acids Res. 2008;36(13):4402-4416.

36. Bradford MM. A rapid and sensitive method for the quantitation of microgram quantities of protein utilizing the principle of protein-dye binding. Anal Biochem. 1976;72(1):248-254.

37. San O, Gören R, Özgür C. Purification of diatomite powder by acid leaching for use in fabrication of porous ceramics. Int J Mine Process. 2009;93(1):6-10.

38. Martucci NM, Rea I, Ruggiero I, et al. A new strategy for label-free detection of lymphoma cancer cells. Biomed Opt Express. 2015;6(4): 1353-1362.

39. De Angelis F, Pujia A, Falcone C, et al. Water soluble nanoporous nanoparticle for in vivo targeted drug delivery and controlled release in B cells tumor context. Nanoscale. 2010;2(10):2230-2236.

40. Loike JD, Silverstein SC. A fluorescence quenching technique using trypan blue to differentiate between attached and ingested glutaraldehyde-fixed red blood cells in phagocytosing murine macrophages. J Immunol Methods. 1983;57(1-3):373-379.
41. Kou L, Sun J, Zhai Y, He Z. The endocytosis and intracellular fate of nanomedicines: implication for rational design. Asian J Pharmaceut Sci. 2013;8(1):1-10.

42. Bannunah AM, Vllasaliu D, Lord J, Stolnik S. Mechanisms of nanoparticle internalization and transport across an intestinal epithelial cell model: effect of size and surface charge. Mol Pharm. 2014;11(12): 4363-4373.

43. Vecchione R, Luciani G, Calcagno V, et al. Multilayered silicabiopolymer nanocapsules with a hydrophobic core and a hydrophilic tunable shell thickness. Nanoscale. 2016;8(16):8798-8809.

44. Love SA, Maurer-Jones MA, Thompson JW, Lin Y, Haynes CL. Assessing nanoparticle toxicity. Annu Rev Anal Chem. 2012;5:181-205.

45. Rosenholm JM, Meinander A, Peuhu E, et al. Targeting of porous hybrid silica nanoparticles to cancer cells. ACS Nano. 2009;3(1):197-206.

46. Lu J, Liong M, Li Z, Zink JI, Tamanoi F. Biocompatibility, biodistribution, and drug-delivery efficiency of mesoporous silica nanoparticles for cancer therapy in animals. Small. 2010;6(16):1794-1805.

47. Varna M, Ratajczak P, Ferreira I, Leboeuf C, Bousquet G, Janin A In vivo distribution of inorganic nanoparticles in preclinical models. J Biomater Nanobiotechnol. 2012;3(2A):269-279.

48. Scarfò L, Ghia P. Reprogramming cell death: BCL2 family inhibition in hematological malignancies. Immunol Lett. 2013;155(1-2):36-39.

49. Garcia-Saez AJ. The secrets of the Bcl-2 family. Cell Death Differ. 2012;19:1733-1740.

50. Ding L, Hu XM, Wu H, et al. Combined transfection of Bcl-2 siRNA and miR-15a oligonucleotides enhanced methotrexate-induced apoptosis in Raji cells. Cancer Biol Med. 2013;10(1):16-21.

51. Hatakeyama $\mathrm{H}$, Ito $\mathrm{E}$, Akita $\mathrm{H}$, et al. A pH-sensitive fusogenic peptide facilitates endosomal escape and greatly enhances the gene silencing of siRNA-containing nanoparticles in vitro and in vivo. J Control Release. 2009;139(2):127-132.

52. Minakuchi Y, Takeshita F, Kosaka N, et al. Atelocollagen-mediated synthetic small interfering RNA delivery for effective gene silencing in vitro and in vivo. Nucleic Acids Res. 2004;32(13):e109.

53. He D, Fang B. Small hairpin RNA targeting at Bcl-2 increases cytarabine induced apoptosis in Raji cells. Acta Biochim Biophys Sin (Shanghai). 2009;41(2):131-136.

54. Nagamatsu K, Tsuchiya F, Oguma K, Maruyama H, Kano R, Hasegawa A The effect of small interfering RNA (siRNA) against the Bcl-2 gene on apoptosis and chemosensitivity in a canine mammary gland tumor cell line. Res Vet Sci. 2008;84(1):49-55.
International Journal of Nanomedicine

\section{Publish your work in this journal}

The International Journal of Nanomedicine is an international, peerreviewed journal focusing on the application of nanotechnology in diagnostics, therapeutics, and drug delivery systems throughout the biomedical field. This journal is indexed on PubMed Central,

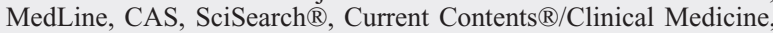

\section{Dovepress}

Journal Citation Reports/Science Edition, EMBase, Scopus and the Elsevier Bibliographic databases. The manuscript management system is completely online and includes a very quick and fair peer-review system, which is all easy to use. Visit http://www.dovepress.com/ testimonials.php to read real quotes from published authors. 